\title{
WETLAND HYDROLOGICAL INTEGRITY ASSESSMENT WITH UNMANNED AERIAL SYSTEMS (UAS)
}

\author{
M. A. Boon ${ }^{\text {ab* } * \text { S. Tesfamichael }}{ }^{\mathrm{c}}$ \\ ${ }^{\text {a }}$ Department of Zoology University of Johannesburg, PO Box 524 Auckland Park, 2006, South Africa. \\ ${ }^{\mathrm{b}}$ Kite Aerial Imagery (Pty) Ltd, 1422 Topaas Street, Waverley, 0186, South Africa - boon@live.co.za \\ ${ }^{\mathrm{c}}$ Department of Geography, Environmental Management and Energy Studies University of Johannesburg, PO Box 524 Auckland \\ Park, 2006, South Africa - sgtesfamichael@uj.ac.za
}

KEY WORDS: Wetland hydrology, Unmanned Aerial System, Structure-from-motion, 3D point clouds, DEM

\begin{abstract}
:
A key component of the health status of a wetland ecosystem is the present hydrological integrity. The analysis of on-site activities that impact on the hydrology of a particular wetland was undertaken using an Unmanned Aerial System (UAS) in combination with field studies. The WET-Health methodology was followed for the hydrological assessment, where wetland health is a measure of the deviation of a wetland's structure and function from its natural reference condition. The extent and nature of activities within the wetland such as impoundments, excavations and indicators of visible damage such as erosion gullies was determined through high resolution UAS mapping using a commercial off-the-shelf digital camera. Structure from Motion (SfM) computer vision techniques were used to derive ultra-high resolution point clouds, orthophotos, digital elevation models (DEMs) and digital terrain models (DTMs). Visual and statistical analyses of the point clouds and surface models were used to derive detailed information useful for enhanced hydrological health assessment of the wetland. The WET-Health hydrology module completed with the aid of the UAS products still indicated that the hydrology of the wetland is completely modified as indicated by the "F" Present Ecological State (PES) category and that the hydrological state of the wetland will deteriorate (change score). However a higher impact score was determined through the enhanced visualisation and completion of scale-appropriate measurements of hydrological features. In conclusion, the use of UAS can significantly enhance the assessment of surface hydrology of wetlands and thereby allow for more effective management, decision making and conservation of wetland ecosystems
\end{abstract}

\section{INTRODUCTION}

Unmanned Aerial Systems (UAS) have become one of the most popular tools for remote sensing applications especially when manned aerial systems and satellite technology and other in situ methods and technology are not effective. These state of the art systems evolved at a considerable pace over the last years (Shahbazi et al., 2014). Off-the-shelf low cost equipment (Fritz et al., 2013) with sophisticated computer vision, robotics and geomatic engineering is available that can provide centimeterlevel resolution and accuracy products generated with low cost digital cameras (Colmina and Molina, 2014). UAS and photogrammetric techniques can generate high-resolution digital elevation models (DEMs) which are amongst the most important spatial information tools to investigate surface hydrology (Ouédraogo et al., 2014).

Westoby et al. (2012) established that Structure-from-Motion (SfM) photogrammetry is a low-cost effective tool for geoscience applications. A SfM derived DEM was compared directly to a similar model obtained using a terrestrial laser scanner (TLS). A decimeter-scale vertical accuracy was achieved even for sites with complex topography and a range of land-covers. An example of one of the study sites that was assessed is a glacially-sculpted bedrock ridge. A total of 800 photographs were taken for the scene reconstruction. Twenty-two orange targets measuring $0.1 \mathrm{~m}$ in diameter were used as Ground Control Points (GCPs). Using a GPS horisontal, vertical, and combined positional accuracies of $0.002,0.002$, and $0.003 \mathrm{~m}$ were achieved.
Lucieer et al. (2013) completed the first study that acquired low altitude aerial photography over Antarctic moss beds using a multi-rotor UAS and SfM photogrammetry. Ultra-high resolution $3 \mathrm{D}$ models were derived from the multi-view aerial photography. Through this study the surface water flow direction and contributing upstream area were determined in order to simulate water availability from snowmelt. Javernick et al. (2014) modeled the topography of shallow braided rivers using SfM photogrammetry and optical bathymetric modeling of inundated areas. This study indicated that this method is a low cost method that can deliver high quality datasets that is competitive with those obtained from more expensive laser scanning and which can be used for the determination of geomorphic change and hydrodynamic modeling. Stöcker et al. (2015) measured gullies by synergetic application of Unmanned Aerial Vehicle (UAV) and close range photogrammetry and obtained comprehensive gully models with a high resolution which can easily be performed at regular intervals.

In previous studies we showed that UAS imagery and derived products can significantly enhance wetland delineation, classification and health assessment (Boon et al., 2016a) and that these imagery can be used for rapid and accurate mapping of wetlands (Boon et al., 2016b). In this study we focused on wetland hydrological assessment (WET-Health) using UAS and photogrammetric techniques. 


\subsection{Aim}

The aim of this study was to evaluate the performance of high resolution UAS imagery and derived products for enhancement of the WET-Health (Macfarlane et al., 2009) assessment of hydrology.

\section{STUDY AREA}

The channelled valley-bottom wetland (Fig. 1) is located on the Kameelzynkraal farm to the east of Pretoria in the Kungwini Local Municipal area, Gauteng Province, South Africa (Boon et al., 2016b).

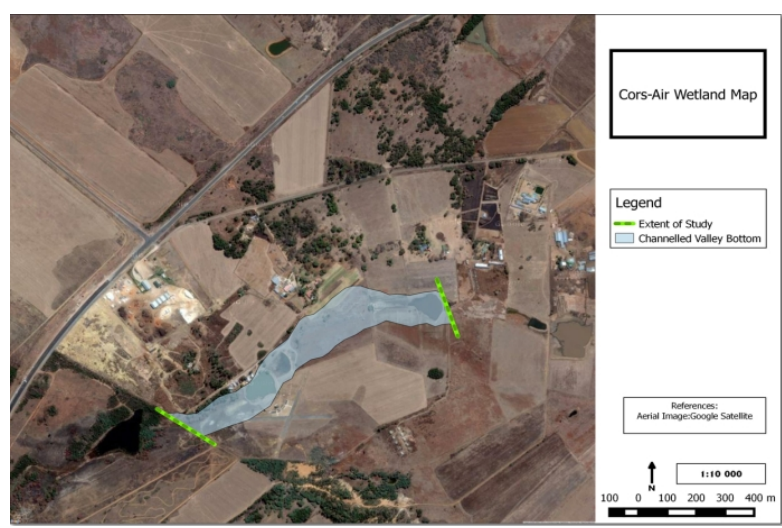

Figure 1. The Cors-Air channelled valley-bottom wetland.

\section{MATERIALS AND METHODS}

The methodology can be divided into four phases indicated in Figure 2 and briefly discussed in sections 3.1 to 3.4.

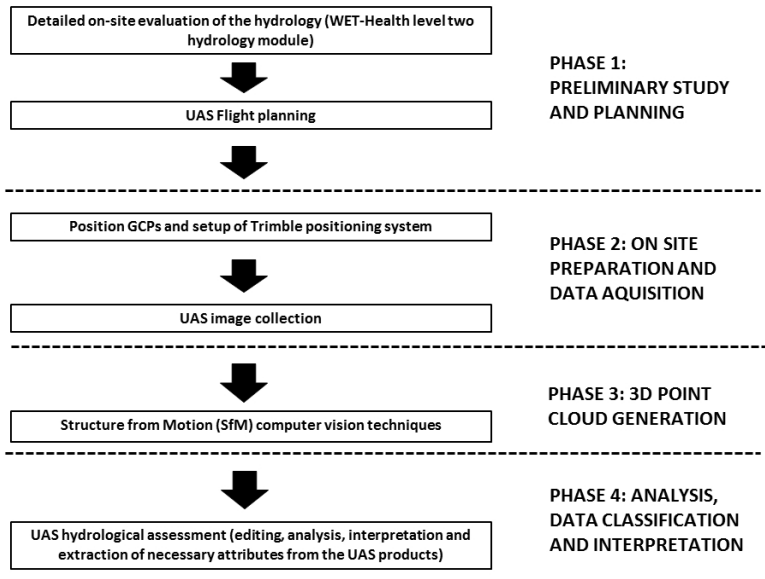

Figure 2. Flow diagram of methodology.

\subsection{Preliminary study and planning}

The detailed on-site and desktop evaluation of the hydrology was completed using the level two WET-Health methodology (Macfarlane et al., 2009). This phase included calculation of study area, number of strips required, photo scale, flying height and percentage of overlapping and preparation of the final flight plan.
A 100ha survey area was selected for the UAS image collection to include a functional wetland area of $15 \mathrm{ha}$ (delineation extent) including the adjacent slopes in order to capture the landscape setting and impacts from the adjacent land uses. More details on the WET-Health methodology used can be found in Boon et al. (2016a) and details on the flight planning and associated parameters in Boon et al. (2016b).

\subsection{On site preparation and data acquisition}

Ground control points (GCPs) were positioned across the site and at the boundaries of the UAS survey area using a Trimble (SPS985 GNSS GPS) site positioning system. An AKS Y-6 MKII multi-rotor UAS and the NIKON D3200 digital camera on a motion compensated gimbal mount were utilised for the collection of the images. Additional information on the GCP and UAS image collection including the UAS setup can be found in Boon et al. (2016b).

\subsection{D point cloud generation}

The completely automated computer vision SfM pipeline provided by Agisoft PhotoScan Professional Version 1.1 commercial software package was used for the $3 \mathrm{D}$ point cloud generation. Boon et al. (2016b) describe the technical methodology followed in more detail. The results were exported in various formats including ASPRS LAS), orthophotos (GeoTIFF, Google Earth KMZ), DEM's and also DTM's (GeoTIFF elevation) from classified point clouds.

\subsection{Analysis, data classification and interpretation}

This step of the methodology includes editing, analysis, interpretation and extraction of necessary attributes from the UAS products. Table 1 indicates the WET-Health factors that have an impact on wetland hydrology that were assessed for both the detailed on-site evaluation of hydrology and the UAV hydrological assessment.

\begin{tabular}{|l|}
\hline 1. Canalisation \\
\hline Slope of wetland \\
\hline Depth of the drains/gullies \\
\hline Density of drains \\
\hline Location of drains/gullies \\
\hline Obstructions in the drains/ gullies \\
\hline 2. Stream channel modification \\
\hline Reduction in length of stream \\
\hline \% increase in cross sectional area of the stream \\
\hline Change in surface roughness \\
\hline 3. Impeding features \\
\hline Extent to which dams or roads interrupt low flows \\
\hline Collective volume of dam/s \\
\hline 4. Impact of direct water losses \\
\hline Alien woody plant type \\
\hline $\begin{array}{l}\text { 5. Magnitude of Impact of recent deposition, infilling } \\
\text { and excavation }\end{array}$ \\
\hline $\begin{array}{l}\text { Effect on vertical drainage properties of the uppermost } \\
\text { soil layer }\end{array}$ \\
\hline Effect on the horizontal movement of water \\
\hline
\end{tabular}

Table 1. Hydrological factors assessed 
The analysis, data classification and interpretation were achieved through a combination of visual analysis of UAS orthophotos, DEMs, DTMs and Dense Point Clouds (DPCs) including extracting of information through profile analysis, 3D mensuration, above ground analysis (AGL), surface water drainage determination from DTM, the calculation of the minimum intensity and the deviation of the intensity of the DPCs (grid statistics calculation). Deviation is calculated for each grid cell by the following formula: $\left.\operatorname{SQRT}\left(\sum\left(\mathrm{x}_{\mathrm{i}}-\mathrm{m}\right)^{2}\right) / \mathrm{N}\right)$ (where SQRT is square root of deviation, $x_{i}$ is a variable sample, $\mathrm{m}$ is the sample mean for that grid cell, and $\mathrm{N}$ is the number of samples. The summation, $\sum$, is from $i=1$ to $i=N$ ). Minimum is calculated as the minimum value of that variable in a given grid cell (Applied Imagery, 2015). The calculations were applied to the point clouds in real time for visualisation. More details on methods and tools used can be found in Boon et al. (2016a).

\section{RESULTS AND DISCUSSION}

The visualisation and interpretation of the high resolution UAS imagery and derived products provided the opportunity to complete a detailed assessment of numerous hydrological factors of the WET-Health hydrological module. Table 2 provide a summary of the products utilised for the assessment. The first column provide information about the root mean squared error (RMSE) and point densities obtained and the second column the ground pixel resolution obtained for the orthophotos, DPCs and DEMs.

\begin{tabular}{|l|l|}
\hline Precision and sampling & UAS products \\
\hline $0.018 \mathrm{~m}$ overall RMSE & $\begin{array}{l}0.018 \text { and 0.025m ground } \\
\text { pixel resolution orthophoto } \\
\text { (wetland area) }\end{array}$ \\
\hline $0.0025 \mathrm{~m}$ vertical RMSE & $\begin{array}{l}0.05 \text { and 0.10m orthohpoto } \\
\text { (full extent) }\end{array}$ \\
\hline $\begin{array}{l}692.7 / \mathrm{m}^{2} \text { point density for } \\
\text { wetland area (high } \\
\text { reconstruction) enabled } \\
\text { accurate detection and } \\
\text { representation of features }\end{array}$ & \begin{tabular}{l} 
(wetland area) \\
\hline $\begin{array}{l}11.8 / \mathrm{m}^{2} \text { point density for } \\
\text { full extent (low } \\
\text { reconstruction) }\end{array}$
\end{tabular} \\
\hline
\end{tabular}

Table 2. Summary of the UAS products utilised.

\subsection{Canalisation}

An accurate slope/profile analysis was calculated for the wetland with the $0.29 \mathrm{~m}$ DTM, resulting in a slope of $1.77 \%$ compared to a minimum of $2.4 \%$ determined using the Google Earth elevation profile tool frequently used by wetland practitioners for desktop evaluation. The depth, density and location of the drains/gullies could easily be determined from the DTMs and DPCs. However the scoring of the depth remained unchanged although a lower density (Figure 3) of drains was determined using the UAS products. It was further determined that the flows in the wetland are moderately to poorly intercepted by the drains/gullies instead of very poorly intercepted. The UAS hydrological assessment also indicated that there is no or limited obstructions in the wetland instead of moderate obstructions.

\subsection{Stream channel modification}

The UAS imagery and derived products provided the possibility to understand and visualise the current scenario Compared with historic data it provides insightful answers and understanding on changes. The impact of historic agricultural practises and sand mining on the reduction of length of the stream could more easily be understood.

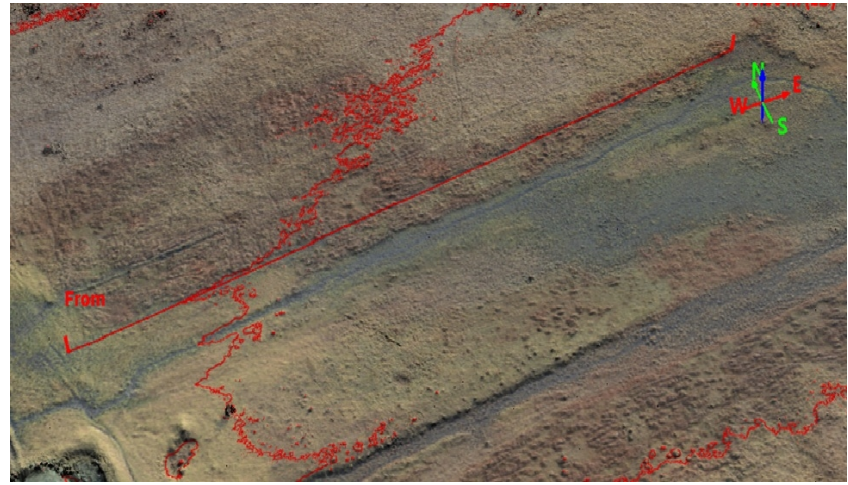

Figure 3. DTM with orthophoto overlay used to determine the density of drains in the wetland

The UAS assessment indicates a higher weighting factor than determined by the on-site evaluation for the determination of the reduction in length of stream. The scoring of the determination of the percentage increase in cross sectional area of the stream remained unchanged. However this system is completely transformed and evidence indicates that historic agriculture already straightened and channelised most of the flow of the study area. The minimum intensity calculation was performed on the DPCs to provide information on the change in surface roughness of the wetland vegetation. A correlation with the roughness and the minimum point intensity was determined. The areas with a minimum point intensity score of just below 45 (green coloration) correlated with areas observed in the field and on the orthophotos as areas with a relative surface roughness (Figure 4).

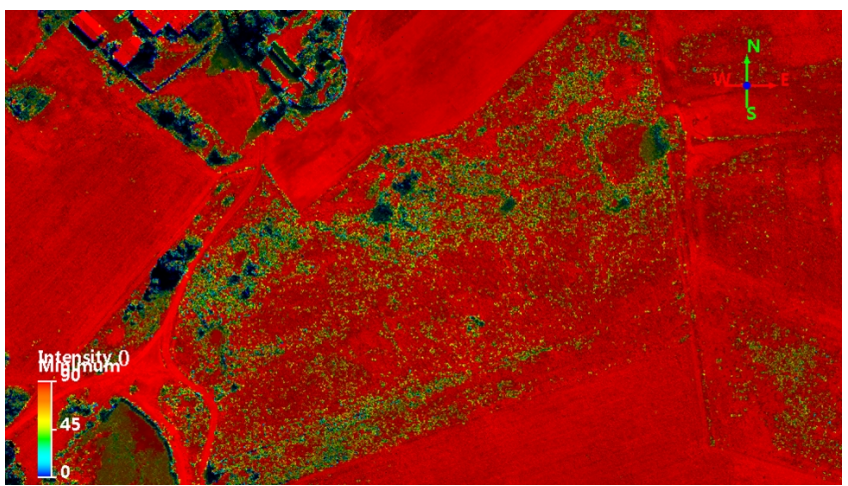

Figure 4. A minimum point intensity score of just below 45

(green coloration) correlated with areas with a relative surface roughness.

The interpretation of the orthophotos in combination with the DEMs (Figure 5) including the AGL analysis of the DPCs provided further insight about the extent and height of the wetland vegetation to determine change in surface roughness in relation to the surface roughness of the channel in its natural state. The UAS assessment indicated that the decrease in roughness is high instead of moderate.

\subsection{Impeding features}

The UAS assessment indicated that there is a moderately high interruption instead of intermediate interruption. The position of the dams within the wetland was accurately determined including the extraction of information such as localities of seepage through the dam walls, the extent of their obstruction and the position and extent of associated features such as overflow canals. 


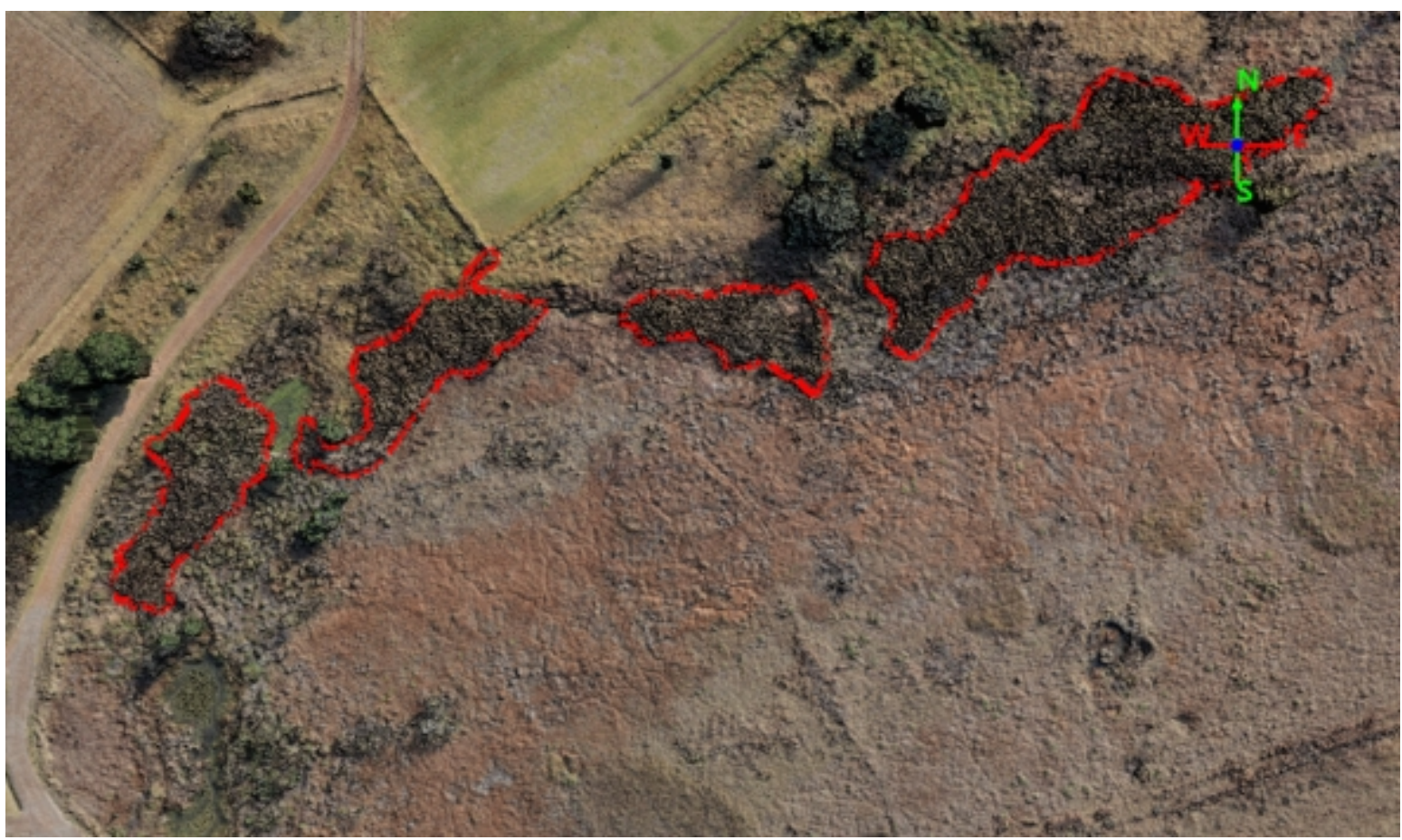

Figure 5. The delineation of wetland vegetation to assist with the determination of surface roughness within the wetland (orthophoto as a texture over DEM).

The scoring of the collective volume of dams remained unchanged. The use of 3D volume determination was possible although all of the earthen dams within the wetland were relatively full.

\subsection{Impact of direct water losses}

Utilising information from the on-site evaluation and some knowledge about the vegetation we identified some of the alien woody plants within and adjacent to the wetland such as the Black wattle (Acacia mearnsii) and Eucalyptus spp from the orthophotos and DPCs. The scoring for this factor remained unchanged.

\subsection{Magnitude of Impact of recent deposition, infilling and excavation}

The UAS orthophotos and DEMs included sufficient detail to relatively accurately identify areas where recent infilling, deposition and excavation has taken place and assisted with the determination of the effect thereof on vertical and horizontal movement of water. The calculation of the intensity deviation of the DPCs further provided valuable insight of areas that was subjected to infilling and deposition such as the airfield and previously mined areas. The scoring for the effect on the vertical movement of water however remained unchanged while the scoring for the horisontal movement indicate a large modification instead of moderate modification. The extraction of the surface water drainage network from the DTM assisted with the determination of overland drainage sources and the effect of the land uses on the surface water runoff and the flow directions

The WET-Health hydrology module completed with the aid of the UAS products still indicate that the hydrology of the wetland is completely modified ("F" PES Category) and that the hydrological state of the wetland will deteriorate (change score). However a higher impact score (activities taking place within the wetland) were determined (Table 3 ).

\begin{tabular}{|l|c|}
\hline Present Hydrological State & F \\
\hline $\begin{array}{l}\text { Trajectory of Change without } \\
\text { rehabilitation interventions. }\end{array}$ & $\downarrow$ \\
\hline $\begin{array}{l}\text { Detailed on-site evaluation of } \\
\text { hydrology Impact Score }\end{array}$ & 9.0 \\
\hline UAS Impact Score & 9.5 \\
\hline
\end{tabular}

Table 3 Hydrological Health of the system and trajectory of change

\section{CONCLUSION}

The use of UAS and photogrammetric techniques can significantly enhance the assessment of surface hydrology of wetlands and thereby allow for more effective management, decision making and conservation of wetland ecosystems. We conclude:

i) The magnitude of canalisation and stream channel modification was easily measured with the UAS data and ensured a more accurate assessment. A better understanding of the magnitude was also achieved through the 3D overview provided by the high resolution 3D UAS products.

ii) Calculation of the minimum intensity of the DPC facilitated the extraction of important information to assist with the determination of the change of the surface roughness of the wetland vegetation. The extent and relative height of the wetland vegetation was also determined from the DEMs, orthophotos and AGL analysis to provide insight into the change of the surface roughness.

iii) The magnitude of impeding features was easily determined from the UAS data. 
iiiv) The magnitude of the impact of recent deposition, infilling and excavation within and adjacent to the wetland was accurately identified from the orthophotos and DEMs. The calculation of the intensity deviation of the DPCs further provided valuable insight.

The outlook of the use UAS imagery is that wetland practitioners can use it in combination with their on-site evaluation of wetlands to enhance their studies and thereby ensure better decision making.

\section{ACKNOWLEDGEMENTS}

We would like to thank Aerial Kopter Solutions (AKS) and the RPAS Training Academy (PTY) Ltd who provided the equipment, resources and expertise to complete the surveying for this project. University of Johannesburg (UJ) Department of Geography, Environmental Management and Energy Studies for the use of their computer to process this dataset and for funding the conference attendance and the UJ Zoology Department that made it possible to undertake this research.

\section{REFERENCES}

Applied Imagery, 2015. Quick Terrain Modeller 8.0.5. Silver Spring, MD: Johns Hopkins Applied Physics Laboratory.

Boon, M.A., Greenfield, R. and Tesfamichael, S., 2016 Wetland Assessment using Unmanned Aerial Vehicle (UAV) Photogrammetry. International Archives of the Photogrammetry, Remote Sensing and Spatial Information Sciences, Prague, Czech Republic, Vol. XLI-B1, pp. 781-788.

Boon, M.A., Greenfield, R., and Tesfamichael, S., 2016. Unmanned Aerial Vehicle (UAV) photogrammetry produces accurate high-resolution orthophotos, point clouds and surface models for mapping wetlands. South African Journal of Geomatics, 5(2), pp. 186-200.

Colomina, I., and Molina, P., 2014. Unmanned aerial systems for photogrammetry and remote sensing: A review. ISPRS Journal of Photogrammetry and Remote Sensing, 92, pp 79-97.

Fritz, A., Kattenborn, T., and Koch, B., 2013. UAV-based photogrammetric point clouds-Tree stem mapping in open stands in comparison to terrestrial laser scanner point clouds. International Archives of the Photogrammetry, Remote Sensing and Spatial Information Sciences, 40, pp. 141-146.

Javernick, L., Brasington, J., and Caruso, B., 2014. Modeling the topography of shallow braided rivers using Structure-fromMotion photogrammetry. Geomorphology, 213,pp. 166-182.

Lucieer, A., Turner, D., King, D., and Robinson, S., 2013. Using an Unmanned Aerial Vehicle (UAV) to capture microtopography of Antarctic moss beds. International Journal of Applied Earth Observation and Geoinformation, 27, pp. 53-62.

Macfarlane, D.M., Kotze, D.C., Ellery, W.N., Walters, D., Koopman, V., Goodman, P., and Goge, C., 2009. WET-Health: A technique for rapidly assessing wetland health. Water Research Commission, Pretoria. WRC Report No TT 340/09

Ouédraogo, M., Degré, A., Debouche, C., and Lisein, J., 2014 The evaluation of unmanned aerial system-based photogrammetry and terrestrial laser scanning to generate DEMs of agricultural watersheds. Geomorphology 214, pp. 229-355
Shahbazi, M., Théau, J., and Ménard, P., 2014. Recent applications of unmanned aerial imagery in natural resource management. GIScience \& Remote Sensing, 2014, pp. 1-27

Stöcker, C., Eltner, A., and Karrasch, P., 2015. Measuring gullies by synergetic application of UAV and close range photogrammetry - A case study from Andalusia, Spain. Catena 132 (2015), pp.1-11

Westoby, M., Brasingon, J., Glasser, N., Hambrey, M., and Reynolds, J., 2012.'Structure from-Motion' photogrammetry: a low-cost, effective tool for geoscience applications. Geomorphology, 179, pp. 300-314. 